\title{
THE EFFECT OF OPIATES ON THE PAIN THRESHOLD IN POST-ADDICTS
}

\author{
By H. L. ANDREWS 1 \\ (United States Public Health Service, United States Public Health Service Hospital, \\ Lexington, Kentucky)
}

(Received for publication October 28, 1942)

One of the characteristics of morphine, when used clinically, is the constancy of its action. In the absence of tolerance, a given dose of morphine can be depended on to give a definite result. With one or two exceptions, this is true regardless of the nature or the anatomical location of the pain, unless this is so severe as to be beyond control by the drug. There is some individual variation in the side effects but the main analgesic action is quite constant.

When the pain-threshold-raising action of morphine is studied by the Hardy-Wolff technique (1), taking care to avoid the development of tolerance, a fairly constant response is again observed (2). The effects are not identical in each individual tested, but are of the same order of magnitude.

This report presents results obtained from pain threshold measurements, using morphine and 7 of its derivatives, in a group of men who had been addicted to opiates but who had received no regular doses of these drugs for at least 6 months prior to the study. The post-addiction period ranged from this minimum to a maximum of 8 years.

\section{METHODS}

A Hardy-Wolff apparatus with a 3-second exposure time was used in this study. The lamp was operated from 110 volt A. C. mains through a voltage-regulating transformer, which reduced line fluctuations to an insignificant amount. The brightness of the lamp was controlled by a Variac and the stimulus intensity was measured with a wattmeter connected in the lamp circuit. Without calibration, this does not permit the radiation intensities to be determined in the basic units of calories per $\mathrm{cm}^{2}$ per second, but since the results of these measurements are usually expressed as a percentage rise above the preinjection level, the wattmeter readings give sufficient information for determining time-action curves. Since it has been shown that the wattmeter readings are linear

1 Present address: National Institute of Health, Bethesda, Maryland. with radiometer readings, the time-action curves will be identical with those obtained with the radiometer.

All patients used in the test were given preliminary training to familiarize them with the apparatus and the procedure. A few were rejected because of their inability to distinguish the various stimulus intensities. In general, however, no trouble was encountered after the first test. Whenever there was any doubt about the results obtained, the particular test was repeated.

All opiates were given subcutaneously or intravenously and in no case did the patient know the drug or the amount he received. An interval of at least 2 weeks elapsed between successive doses, to avoid complications due to the development of tolerance. At least 5 consistent threshold readings were obtained before administering the drug. After the medication, thresholds were determined at 10 or 15 minute intervals until the values returned to the pre-injection level.

\section{RESULTS}

The pre-injection pain threshold levels were quite comparable with those obtained with nonaddicts. Several patients reported that they were "nervous," were unable to stand pain and mental stress, and that these had been contributing factors to their addiction but there was no tendency of the group toward an abnormally low threshold to the type of stimulus used in the present study.

There was, however, an abnormally low response following the administration of morphine and it soon became apparent that to obtain measurable increases in threshold, comparatively large doses would be required. A minimum of $20 \mathrm{mgm}$. of morphine was chosen, and all results obtained with morphine derivatives are compared to this dosage.

Morhpine. One of the striking results is the individual variation in the response obtained with a uniform dose (Figure 1-A). In no case was the threshold raising effect of $20 \mathrm{mgm}$. more than a fraction of that anticipated from the work of Wolff, Hardy, and Goodell (2), and in some cases, a definite lowering of the threshold followed the injection. Seven patients, of a total of 
A-INOIVIDUAL VARIATIONS

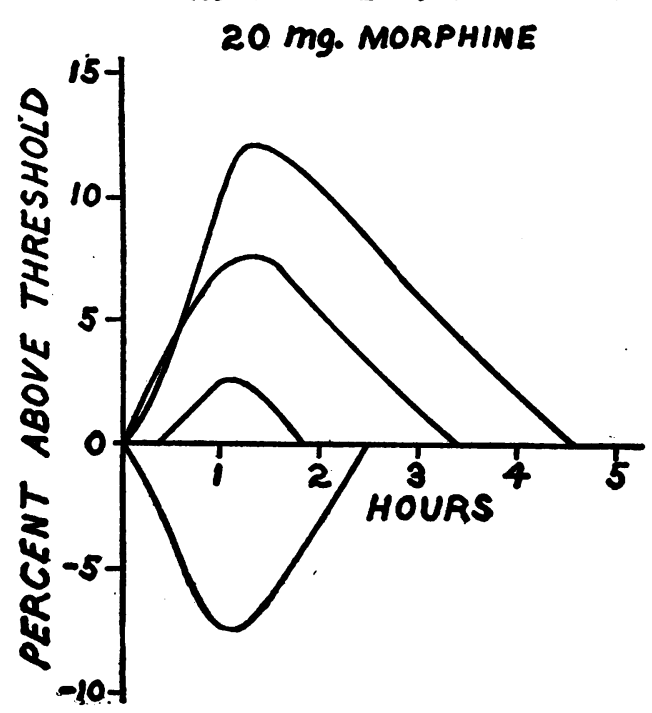

B-EFFECT OF DOSE-3 CASES

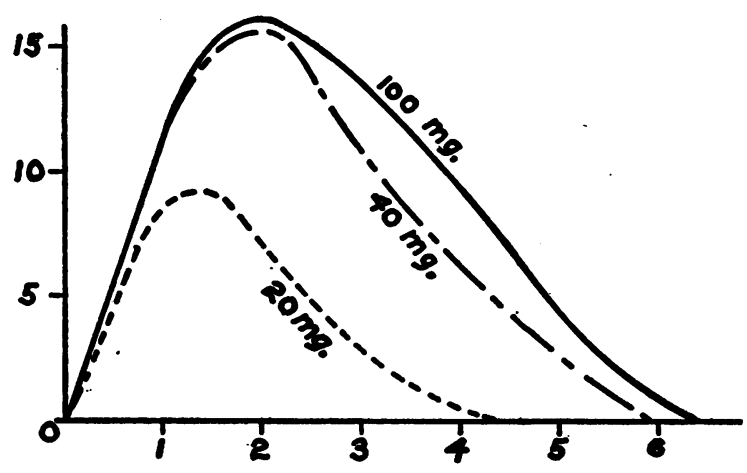

Fig. 1. The Effect of Opiates on the Pain Threshold in Post-Addicts

A. Responses from 4 post-addicts showing the large individual variations obtained with this group. On retest, each case consistently repeated his typical response pattern.

B. Mean curves from a group of 3 cases for 3 dosages. Even with a dose of $100 \mathrm{mgm}$., the maximum increase in threshold barely exceeded 15 per cent.

57 , consistently showed this reversed effect which appears to be genuine, for an essentially similar result was obtained at each re-test. This negative effect is not a true reversal, for in these cases, sufficiently large doses produced a positive threshold-raising action. The response obtained from a single dose of morphine does not appear to be related to the length or intensity of previous addictions, nor to the length of time following the last addiction.

Patients showing this reversed effect were not used in studying the morphine derivatives and because of individual variations, each group receiving a derivative was compared with the same group with morphine.

With larger doses of morphine an increased effect is obtained (Figure 1-B), but a saturation effect is observed (2) and the maximum effect of $100 \mathrm{mgm}$. is only slightly greater than that of 40 $\mathrm{mgm}$. The total effect in per cent hours, obtained by measuring the area under the curves with a planimeter, increased somewhat, even up to the $100 \mathrm{mgm}$. dose, because of the prolonged time of action of the larger doses. The total effects in order of ascending doses of 20,40 , and $100 \mathrm{mgm}$. are 19.3, 49.0, and 58.2 per cent hours respec- tively. From the curves of Wolff, Hardy, and Goodell (2), the total effect of $20 \mathrm{mgm}$. would be expected to be about 320 point hours, or 16.6 times that observed in the post-addict. No comparative data are available for the larger doses.

It is of interest to note that the time at which the effect becomes maximal is approximately the same as that found with non-addicts (1.5 hours) and that this time is increased with the larger doses.

The subjective effects of the largest doses were marked, but the smaller doses were tolerated much better than would be the case with non-addicts. Occasional vomiting was encountered with 100 $\mathrm{mgm}$. and $40 \mathrm{mgm}$. but was absent with $20 \mathrm{mgm}$. The most consistent finding was myosis. Depression was marked with $100 \mathrm{mgm}$. but was absent with the smaller doses.

Codeine. The work of Himmelsbach (3) indicates that the ability of codeine to satisfy existing physical dependence in man is only 0.19 that of morphine. In cats, Eddy (4) found the analgesic effect to be 0.09 that of morphine. The painthreshold-raising effect of $100 \mathrm{mgm}$. of codeine is shown in Figure 2, compared to the effect of 20 $\mathrm{mgm}$. of morphine in the same patients. The 

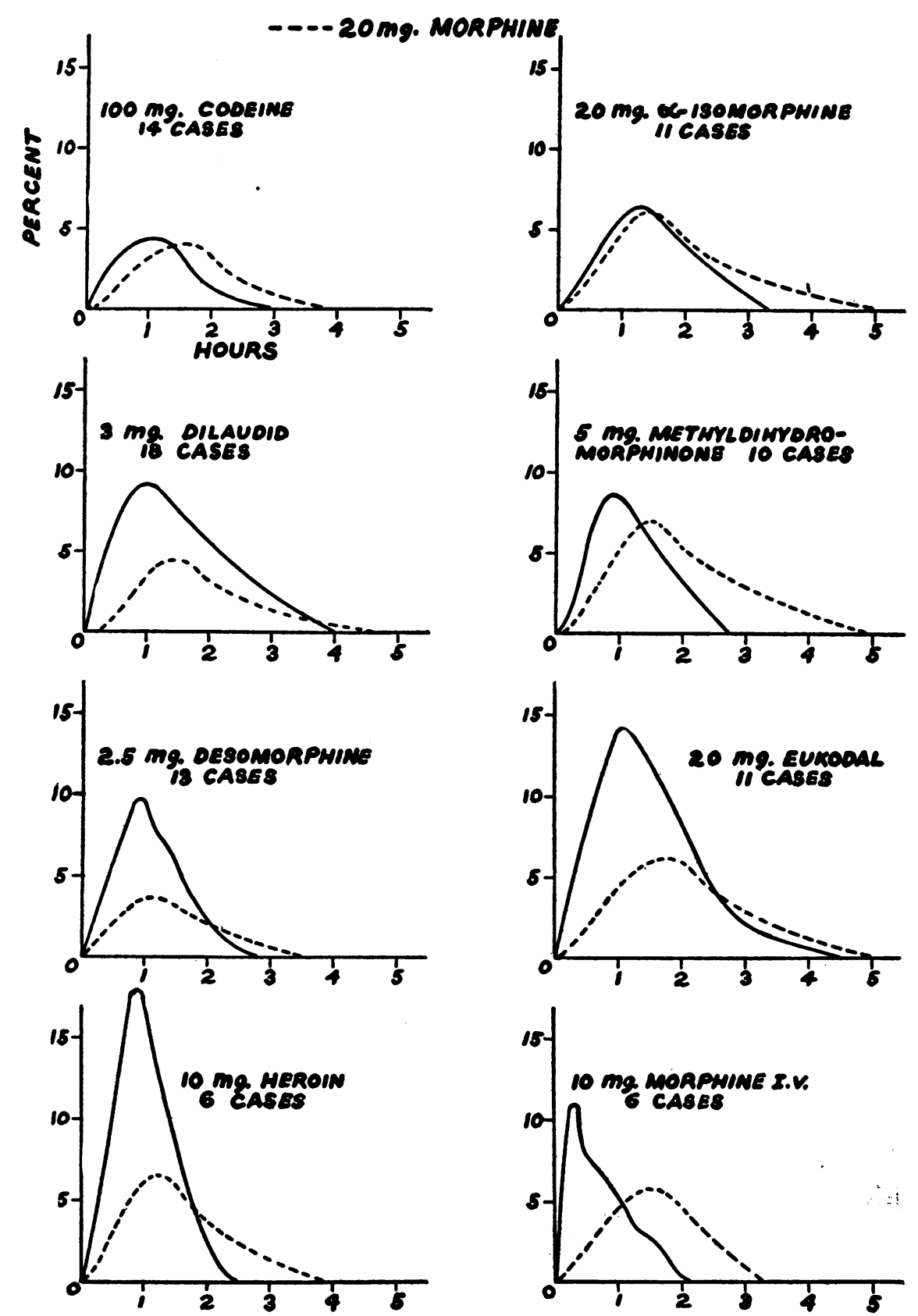

Fig. 2. The Pain-Threshold-Raising Effect of Various Opiates in the Post-Addict

The mean effect of each drug is plotted as per cent of the mean effect of morphine in the same group.

maximum effect of the codeine was quite comparable to that of morphine, but the maximum effect was attained earlier and the duration was shorter. This is surprising since other studies indicate that the duration of codeine action is at least as long as that of morphine. The total effect of the codeine was 6.7 per cent hours, compared to 7.7 for morphine.

Alpha-isomorphine. From substitution studies (3) this drug appears to be 1.4 times as potent as 
morphine, while the work on cats (4) shows an analgesic potency ratio of 0.9 . The effect of 20 mgm. is compared with morphine in Figure 2. The maximum effects are about equal for the 2 drugs but the alpha isomer has a somewhat shorter time of action. The total effects were 11.2 per cent hours for the alpha isomer and 12.9 for morphine.

Dihydromorphinone (Dilaudid). The substitution studies indicate that this drug is 7 times as potent as morphine, while the analgesia studies of Eddy on cats gives a ratio of 4.4. Pain threshold studies in man (2) suggest a ratio of about 10 . In Figure 2 is shown a comparison of the effect of $3 \mathrm{mgm}$. of Dilaudid and $20 \mathrm{mgm}$. of morphine. With a dosage ratio of approximately $1: 7$, the total effect of the Dilaudid was 19.0 per cent hours to be compared to only 8.9 per cent hours for morphine. It appears that in the post-addict, Dilaudid is considerably more effective than would be anticipated from other data.

Methyldihydromorphinone. Substitution was not entirely satisfactory (5) but indicates that the physical dependence-satisfying action is about 7.2 times that of morphine. The analgesia studies on cats yield a ratio of 7.5 with a duration shorter than morphine. Wolff, Hardy, and Goodell (2) report a ratio of about 4.5 from pain threshold measurements in man, and Lee (6) found a ratio of about 2 from the clinical use of the drug in the relief of pain. Using a dose ratio of 4 , it appears that the total effect of methyldihydromorphinone is less than that of morphine, the figures being 12.2 and 15.5 , respectively. The maximum effect is somewhat greater than with morphine.

Dihydrodesoxymorphine-D. (Desomorphine). Himmelsbach (5) reported an addiction-satisfying ratio of 5 and Eddy (4) an analgesia ratio of 9.4. The clinical studies of Lee (6) indicate a ratio of 11.3. When given in $1 / 8$ of the morphine dosage, the total effect was 12.2 per cent hours, to be compared with only 6.8 for morphine. Most of this difference came from the high maximum value which was more than twice that obtained with morphine.

Dihydrohydroxycodeinone (Eukodal). The addiction-satisfying potency is about 0.67 that of morphine (4). Eddy (4) reports an analgesic potency ratio of 0.51 . With a dose of $20 \mathrm{mgm}$., the total effect of 26.0 per cent hours was almost double the effect of the equal dose of morphine which was 14.0 per cent hours. The maximum effect was more than twice that of morphine and occurred earlier.

Diacetylmorphine (Heroin). Eddy (4) reports an analgesic effectiveness in cats of 1.8 . When given in a dose $1 / 2$ that of morphine, heroin produces a prompt rise in pain threshold. The total effectiveness is 19.7 per cent hours to be compared with 11.6 per cent hours for morphine.

Intravenous morphine. There are no comparative data, but an effect having a rapid onset and a short duration would be anticipated. This is actually the case, for a dose of $10 \mathrm{mgm}$. shows a maximum effect of 11 per cent at 18 minutes, compared to the peak of 5.9 per cent at 1.5 hours, for $20 \mathrm{mgm}$. given subcutaneously. The total effect was the same from both curves, 10.4 per cent hours.

The results described above are summarized in Table I.

TABLE I

\begin{tabular}{|c|c|c|c|c|c|c|c|}
\hline \multirow{2}{*}{ Drug } & \multicolumn{4}{|c|}{$\begin{array}{l}\text { Effectiveness relative to } \\
\text { morphine measured by }\end{array}$} & \multicolumn{3}{|c|}{$\begin{array}{l}\text { Effectiveness rela- } \\
\text { tive to morphine } \\
\text { on pain threshold } \\
\text { in post-addicts }\end{array}$} \\
\hline & $\begin{array}{l}\text { Sub- } \\
\text { stitu- } \\
\text { tion* }\end{array}$ & $\begin{array}{c}\text { Anal- } \\
\text { gesia } \\
\text { in catst }\end{array}$ & $\begin{array}{l}\text { Pain } \\
\text { thresh- } \\
\text { old in } \\
\text { man } \$\end{array}$ & $\begin{array}{l}\text { Chlin- } \\
\text { ical } \\
\text { uses }\end{array}$ & Dose & $\underset{\text { mumi- }}{\text { Maxiect }}$ & $\begin{array}{l}\text { Total } \\
\text { effect }\end{array}$ \\
\hline $\begin{array}{l}\text { Morphine } \\
\text { Codeine } \\
\text { a-isomorphine } \\
\text { Dilaudid } \\
\text { Methyldihydro- } \\
\text { morphinone } \\
\text { Desomorphine } \\
\text { Eukodal } \\
\text { Heroin } \\
\text { Morphine (i.v.) }\end{array}$ & $\begin{array}{l}1.0 \\
0.19 \\
1.4 \\
7.0 \\
7.2 \\
5.0 \\
0.67\end{array}$ & $\begin{array}{c}1.0 \\
0.09 \\
0.9 \\
4.4 \\
10.7 \\
9.4 \\
0.51 \\
1.8\end{array}$ & $\begin{array}{c}1.0 \\
0.10 \\
10.0 \\
4.5\end{array}$ & $\begin{array}{r}2.0 \\
11.3\end{array}$ & $\begin{array}{c}m g m . \\
20 \\
100 \\
20 \\
3 \\
5 \\
2.5 \\
20 \\
10 \\
10\end{array}$ & $\begin{array}{l}1.0 \\
0.22 \\
1.0 \\
13.3 \\
4.8 \\
20.8 \\
2.3 \\
5.6 \\
3.8\end{array}$ & $\begin{array}{c}1.0 \\
0.13 \\
0.9 \\
14.2 \\
3.1 \\
14.3 \\
1.9 \\
3.4 \\
2.0\end{array}$ \\
\hline
\end{tabular}

* Himmelsbach (3 to 5).

t Eddy (4).

$\$$ Wolff and Hardy (2).

8 Lee (6).

The relative effectiveness was calculated from the relative maxima of the time-action curves and also from the total areas under these curves.

\section{DISCUSSION}

The most striking result is the low thresholdraising effect of even a massive dose of morphine. The pre-injection threshold is practically normal but the response following the drug is only a fraction of that obtained in non-addicts. It has been suggested (7) that the first addiction produces certain irreversible changes which might be thought 
of as residual tolerance. The present studies confirm this suggestion and indicate that the changes in the pain threshold mechanism are strongly irreversible. Since the effect appears to increase almost linearly with dosage until a saturation level is reached, it appears that there is no barrier to be broken down before the threshold raising action can take place, but rather that the organism has become much less sensitive to this action.

The large individual variations obtained from a standard dose are very interesting and it is unfortunate that nothing has been found in the addiction histories which will correlate with the variations in response. Even those cases who repeatedly show a reduction in pain threshold following morphine have no obviously unusual factors in their make-up which might account for this reversed effect.

In spite of the fact that the post-addict shows a greatly reduced pain threshold response to morphine, the clinical relief of pain is accomplished at this Hospital with no significant increase in morphine dosage over that used with non-addicts. (I am indebted to Passed Assistant Surgeon Leo D. O'Kane for this information.) This fact supports the suggestion (2) that the pain-threshold-raising action is only one part of the process by which relief of pain is achieved, and indeed suggests that this is a relatively unimportant part.

The reduction in pain-threshold-raising effect appears to be somewhat specific, for the response of a group of 12 post-addicts to 10 grains of acetylsalicylic acid, a typical non-opiate, was 76 per cent of that obtained from normals. A further example of this specificity was obtained from a group of post-addicts who showed a reduced response to morphine but an almost normal threshold increase following Demerol. When Demerol was administered regularly, tolerance developed, and the rise in pain threshold was greatly reduced, and has remained so for many months after withdrawal (8). The series of morphine derivatives seemed to provide a suitable tool for studying this specificity, but unfortunately, the results are not entirely satisfactory because of uncertainties in the effects to be expected. A few results, however, appear to be clear-cut. The present results indicate that Dilaudid, Desomorphine, Eukodal, and Heroin are comparatively more effective in the post-addict than other data would predict. Even with these drugs, the threshold raising effect is only a small fraction of that anticipated from normals.

It should be noted (Figure 2) that all of the more effective drugs are those which are comparatively short acting and which reach a maximum earlier than morphine. If the phenomenon of residual tolerance is a retained ability to rapidly destroy or conjugate opiates and render them innocuous, the more rapidly acting drugs would be expected to appear unduly effective since they would be exposed to this action for a shorter time. This suggestion is supported by the results of intravenous administration, where a doubling of the total effectiveness was observed.

\section{CONCLUSIONS}

When the pain-threshold-raising effect of morphine and its derivatives is tested in post-addicts, a variable but greatly reduced response is found. Results with certain derivatives suggest that this reduced response may be somewhat specific. The abnormally low response could be explained by a retained ability to destroy opiates rapidly. The measurements of pain threshold appear to have little connection with the clinical relief of pain, for this is accomplished in the post-addict with little or no increase in the morphine dosage.

\section{BIBLIOGRAPHY}

1. Hardy, J. D., Wolff, H. G., and Goodell, H., Studies on pain. A new method for measuring pain threshold: Observations on spatial summation of pain. J. Clin. Invest., 1940, 19, 649.

2. Wolff, H. G., Hardy, J. D., and Goodell, H., Studies on pain. Measurement of the effect of morphine, codeine, and other opiates on the pain threshold and an analysis of their relation to the pain experience. J. Clin. Invest., 1940, 19, 659.

3. Himmelsbach, C. K., The effects of certain chemical changes on the addiction characteristics of drugs of the morphine, codeine series. J. Pharmacol. and Exper. Therap., 1941, 71, 42.

4. Small, L. F., Eddy, N. B., Mosettig, E., and Himmelsbach, C. K., Studies on drug addiction. Supplement No. 138 to the Public Health Reports, 1938.

5. Himmelsbach, C. K., Studies of certain addiction characteristics of (a) dihydromorphine ("paramorphan"), (b) dihydrodesoxymorphine-D ("desomorphine"), (c) dihydrodesoxycodeine-D ("desocodeine"), and (d) methyldihydromorphinone ("metopon"). J. Pharmacol. and Exper. Therap., 1939, 67, 239. 
6. Lee, L. E., Jr., Studies of morphine, codeine and their derivatives. XVI. Clinical studies of morphine, methyldihydromorphinone (metopon) and dihydrodesoxymorphine-D (desomorphine). J. Pharmacol. and Exper. Therap., 1942, 75, 161.
7. Andrews, H. L., Brain potentials and morphine addiction. Psychosom. Med., 1941, 3, 399.

8. Andrews, H. L., The development of tolerance to demerol. J. Pharmacol. and Exper. Therap., 1942, 75, 338. 